\title{
Endoscopic drainage of pancreatic pseudocysts
}

Claude Liguory, MD, Jean FrançoIs LeFEBVRE, MD, Gary C VITALE, MD

\begin{abstract}
Endoscopic drainage of pancreatic pseudocysts was attempted in 17 patients over an eight year period. There were nine cysts located in the head of the pancreas, six in the body and two in the tail. Endoscopic retrograde cholangiopancreatography was performed in all cases and the pancreatic duct satisfactorily opacified in 16 of the 17 patients. This study identified a communication with the pancreatic duct in seven cases. There were two cases in which multiple cysts were present; in each, one cyst was drained endoscopically and the others surgically. Endoscopic drainage of the cyst was immediately possible in 16 of 17 cases (94\%). Late follow-up (mean 26 months) documented cyst disappearance in 11 cases $(69 \%)$. None of the five patients with persistent cysts has required secondary surgical intervention, and the cysts are asymptomatic and stable or decreasing in size by serial scanning. There was one case $(6 \%)$ in which a pseudocyst recurred following initial resolution. There were two complications (12\%) requiring surgical intervention: gastrointestinal perforation with peritonitis in one patient and hemorrhage at the cyst margin from an arterial bleeder in another. There were no deaths at 30 days, but in one case a recurrent acute necrotizing pancreatitis occurred 36 days following endoscopic drainage and the patient died. This death was felt to be unrelated to the endoscopic procedure. In conclusion, internal drainage of pancreatic pseudocysts by endoscopic means can be proposed as an alternative to surgical drainage when the cyst can be identified as bulging into the stomach or duodenum. Immediate drainage is usually effective with a minimal long term recurrence rate. Can J Gastroenterol 1990;4(9):568-571
\end{abstract}

Key Words: Endoscopic cystostomy, Pancreatic cysts

\section{Le drainage endoscopique des pseudokystes pancréatiques}

RESUME: Le drainage endoscopique des pseudokystes pancréatiques a été tenté chez 17 patients sur une période de huit ans. Neuf kystes étaient situés dans la tête du pancréas, six dans le corps et deux dans la queue. Une cholangiopancréatographie rétrograde endoscopique a été effectuée dans chaque cas et il y a eu opacification satisfaisante du canal pancréatique chez 16 des 17

Clinique de L'Alma, Paris, France and University of Louisville, Kentucky, USA

Correspondence and reprints: Dr C Liguory, 7 Avenue de Breteville, 92200 Neuilly Sur Seine, France. Telephone (1) 47220440
$\mathrm{T}$ HE TREATMENT OF PANCREATIC pseudocysts remains somewhat controversial with respect to necessity, timing and method of intervention $(1,2)$. The advent of endoscopic retrograde cholangiopancreatography (ERCP), abdominal ultrasound and computed tomography scanning has al. lowed a more comprehensive look into the natural history of pseudocysts both before and after treatment $(3,4)$. It is clear that given the relatively benign course of this disease, a nonsurgical op. tion would be very appealing, if success. ful. Endoscopic pancreatic cystoenterostomy has been reported in the treatment of pseudocysts complicating acute or chronic pancreatitis and represents a treatment option in selected anatomic configurations $(5-8)$. The current report details the method, results and potential complications of this technique in the management of the pancreatic pseudocyst.

\section{PATIENTS AND METHODS}

Endoscopic drainage of pancreatic pseudocysts was attempted in 17 patients over an eight year period end. ing in May 1989. There were 15 men and two women with mean age $53 \pm 12$ years (range 34 to 72 ). All pseudocysts were associated with either acute (seven patients) or chronic (10 
patients. L'étude a relevé une communication avec le canal pancréatique dans sept cas. Des kystes multiples étaient présents dans deux cas; pour chacun d'eux, l'un des kystes a été drainé par endoscopie et les autres chirurgicalement. Le drainage endoscopique du kyste était immédiatement possible chez 16 des 17 patients $(94 \%)$. Un suivi tardif (moyenne de 26 mois) a confirmé la disparition des kystes dans 11 cas (69\%). Aucun des cinq patients atteints de kystes persistants n'a requis une seconde intervention chirurgicale; les kystes sont asymptomatiques et stables ou diminuent de grosseur, selon des échographies périodiques. Dans un cas $(6 \%)$, un pseudokyste a récidivé après sa résolution initiale. Des complications nécessitant une intervention chirurgicale se sont déclarées chez deux sujets $(12 \%)$ : une perforation gastrointestinale avec péritonite chez l'un, et une hémorragie survenue à la marge du kyste et alimentée par une artère chez l'autre. Aucun décès n'était noté à 30 jours, mais un des patients a été victime d'une rechute fatale de pancréatite aiguë nécrosante 36 jours après un drainage endoscopique. On estime que ce décès n'était pas relié à la procédure endoscopique. En conclusion, le drainage interne des pseudokystes pancréatiques par voie endoscopique peut être proposé à titre de solution de rechange au drainage chirurgical quand le kyste est saillant au niveau de l'estomac ou du duodénum. Le drainage immédiat est habituellement efficace et s'accompagne d'un taux minime de récidive à long terme.

patients) pancreatitis. Clinical presenting symptoms are delineated in Table 1. The indications for pseudocyst drainage were clinical symptoms or increasing volume in 13 patients, biliary compression in two, spontaneous fistulization in one and recurrence after surgical treatment in une. Mean follow-up after cyst drainage was 26 months (range three to 80). All patients underwent either $a b$ dominal ultrasound or computed tomography scanning to document resolution of the cyst. Repeat ERCP was not routinely performed.

The cysts could be identified ultrasonographically in 16 , by abdominal computed tomography scan in 13 , and in all cases by endoscopically identified internal indentation of the adjacent digestive tract. The mean size of the cysts was $69 \pm 44 \mathrm{~mm}$ (range 30 to 200). In two cases there were multiple cysts, and only one cyst in each patient was drained endoscopically; surgical drainage was accomplished for the remaining cysts in these patients. Of the cysts drained endoscopically, there were nine located in the head of the pancreas, six in the body and two in the tail. The cephalic cysts resulted in a compression of the second part of the duodenum; cysts of the body and tail resulted in gastric compression. ERCP was performed in all cases to define the ductal anatomy and to determine the presence or absence of a major ductal communication to the cyst. The pancreatic duct was satisfactorily opacified in 16 of 17 patients.

Cystoenterostomy was performed by making a short incision of approximately $5 \mathrm{~mm}$ with the diathermy knife, which was enlarged to a size of 10 to 15 $\mathrm{mm}$ after assessment of cyst fluid and opacification of the cyst cavity. The point of maximum compression on the enteric lumen was used as a point for drainage. Hemorrhage, when present, was controlled using the diathermy probe. Nasopancreatic cyst drains were placed when possible to allow irrigation of the cyst cavity and assure adequate continued drainage following local tissue trauma.

\section{RESULTS}

ERCP identified a communication with pancreatic ducts in seven cases. In two cases of chronic pancreatitis, a pancreas divisum was discovered; one had an enlarged ventral and one an enlarged dorsal pancreatic duct. Pancreatic ductal dilation was seen in eight cases and stenosis in three. The pancreatic duct was normal in three cases (Table 2).

Drainage of the cysts was immediately possible in 16 of 17 cases (94\%). Late follow-up documented cyst disappearance in 11 of these $16(69 \%)$. Of
TABLE 1

Clinical presenting symptoms in 17 patients with pancreatic pseudocysts associated with pancreatitis

Pain 13

Weight loss

Cholestasis

Fever

Pseudochylous ascites

Epigastric mass

5

Values given are numbers of patients

\section{TABLE 2}

Results of endoscopic retrograde cholangiopancreatography in 17 patients with pancreatic pseudocysts associated with pancreatitis

Enlarged Wirsung duct

Pancreas divisum with enlarged Ventral duct

Dorsal duct

Wirsung duct stenosis

Normal Wirsung

Failure of opacification

8

1

1

3

3

1

the five patients with persistent cysts by echo or computed tomography, the pseudocyst was clinically asymptomatic and appeared stable or reducing in size on serial scans. None of these has required secondary surgical intervention to date. There was one case $(6 \%)$ in which a pseudocyst recurred following initial resolution. This recurrent cyst was in proximity to the original cyst and it was not possible to tell whether it represented treatment failure or progression of disease with subsequent cyst formation.

There were two significant complications $(12 \%)$ requiring surgical intervention. An early complication of GI perforation with peritonitis occurred in one patient and required emergency laparotomy the day following endoscopic drainage. Hemorrhage requiring transfusion was seen in one patient, and this patient required emergency surgery 15 days after the endoscopic procedure. At surgery, an arterial bleeder was identified at the cyst margin and cystojejunostomy was performed after ligation of the bleeder. There were no deaths at 30 days. In one case a recurrent acute necrotizing pancreatitis occurred 36 days after endoscopic drainage and the patient died. In reviewing the course of the patient, it was felt that the death was not related 
TABLE 3

Late results of endoscopic drainage

\begin{tabular}{ll}
\hline Cyst disappearance & 11 \\
Surgery & 1 \\
Emergency (bleeding day 8 ) & 2 \\
Complementary & 1 \\
Death (day 36) & 1 \\
(recurrence of acute pancreatitis) \\
Follow-up 26 months (2 to 80) \\
\hline
\end{tabular}

to endoscopic drainage, as the patient had done well following the procedure. Outcomes are shown in Table 3.

\section{DISCUSSION}

The pancreatic pseudocyst accompanying acute pancreatitis may be transient; spontaneous resolution has been documented in up to $90 \%$ of cases $(2,3,9)$. Their drainage is more difficult both surgically and nonsurgically because of the nature of the cyst wall and the heterogeneous cyst contents. The early cyst wall is thick but phlegmonous in nature and frequently does not adhere well to adjacent gastrointestinal structures. Thus, surgical drainage may not be possible at this stage, since a suture will not hold to the cyst wall, and may be more difficult with higher risk of anastomotic leakage since the plane between the pseudocyst and the stomach or duodenum may not be completely obliterated as with the more chronic cyst (10). Thus, endoscopic cystoenterostomy may be more useful in these earlier cases, if clinically indicated, since surgery is otherwise only infrequently required following acute pancreatitis. Due to the high spontaneous resolution rate, cyst drainage in this group by any method should be limited to cysts persisting beyond several months with documented maturation by serial scanning, rapidly enlarging and clinically symptomatic cysts, or cysts with progressive gastrointestinal or biliary compression.

In cases of chronic pancreatitis, the spontaneous pseudocyst remission rate is not as high (11) and the long term complications of cyst hemorrhage, perforation or infection are more frequent $(33.5 \%)$. Thus, elective cyst drainage is less controversial in this group and is often simpler both surgically and nonsurgically due to the cyst wall and con- tent characteristics (12). The walls are more clearly defined and adherent to adjacent gastrointestinal structures and the cyst contents more fluid, facilitating adequate drainage. Precise indications for cyst drainage in this group are ill defined because they are frequently asymptomatic or have symptoms inseparable from the primary pancreatic pathology. Clearly, progressive enlargement or suspicion of superinfection would mandate drainage. Frequent indications for drainage in this group include gastrointestinal or biliary compression, chronicity, risk of future complications of infection, perforation or internal hemorrhage (13).

The surgical diversion of pancreatic cysts has associated severe complications such as infection, bleeding or perforation in 10 to $25 \%$ with mortality rates from 5 to $12 \%$. Thus, surgical intervention, while highly successful, does incur significant morbidity in this chronically ill patient population. Recurrence rates following surgery are around $5 \%(2,10,14)$. The complication, mortality and recurrence rates in the current study compare favorably with surgical treatment. The long term cyst disappearance rate of $68 \%$ may be felt to be low compared to surgical series, but documentation of cyst disappearance following surgical drainage is not uniform in all series. The true rate and time course of cyst cavity disappearance is often not clear. The bottom line of symptom resolution and stable or decreasing cyst size by serial scanning remains an adequate measure of satisfactory outcome. Three patients ultimately required surgical intervention in the study - two for acute complications of perforation and hemorrhage and one for failure of initial cyst drainage. One might thus quote a nonsurgical failure rate of $18 \%$. The avoidance of surgery in $82 \%$ of the present patients over a mean follow-up period of 26 months was felt to be an important positive outcome.

The first nonsurgical drainage procedures were percutaneous, $x$-rayguided, pseudocyst punctures with drain placement (15-17). Ultrasound or computed tomography scan guidance is now routinely used. One is somewhat limited by the size of drainage catheters that can be placed, and maintenance of catheter patency can be difficult. The viscosity and heterogeneous particulate nature of the cyst fluid in acute pancreatitis make this method of drainage somewhat less desirable than endoscopic or surgical drainage. Additionally, although it remains to be conclusively shown, internal drainage is, a priori, preferable to external drainage with regard to infection. Immediate success rates of 50 to $100 \%$ with needle puncture and drainage are quoted in the literature, but a high recurrence rate of greater than 50\% makes external drainage a less than optimal choice if endoscopic techniques are suitable. This technique should be reserved for patients who are higher surgical risks and when endoscopic pseudocyst visualization is not possible.

Laugier et al (18), reporting their experience with the combined results of percutaneous and endoscopic drainage of 35 pancreatic pseudocysts, note an immediate success rate of $88.5 \%$ with no mortality, and a $14.3 \%$ complication rate. Cremer et al (19) perforated 13 cystoduodenostomies and five cystogastrostomies without complications or mortality and with complete cyst disappearance in 15 cases $(83.3 \%)$. There were two recurrences and two incomplete drainages in that series. These figures are comparable to the present findings in terms of early technical failure and recurrence rates. Thus, overall, experience with endoscopic drainage is quite promising and at present the main limitation of this technique is the necessity for visual bulging of the pseudocyst into the stomach or duodenum prior to drainage. These early results may improve as imaging techniques continue to advance over the next decade, particularly in the area of endoscopic ultrasound. More accurate pseudocyst localization would increase the number of patients who could benefit from endoscopic treatment.

In conclusion, internal drainage of pancreatic pseudocysts by endoscopic means has a morbidity and mortality lower than surgical pseudocyst drainage and can be proposed as the treatment of 
choice when the cyst can be identified as bulging into the stomach or duodenum. Immediate drainage is usually efficient with a minimal long term recurrence rate.

\section{REFERENCES}

1. Grace RR, Jordon PH. Unresolved problems of pancreatic pseudocysts. Ann Surg 1976;184:16-21.

2. Sankaran S, Walt AJ. The natural and unnatural history of pancreatic pseudocysts. Br J Surg 1975;62:37-44.

3. Bradley EL, Clements JL, Gonzales AC. The natural history of pancreatic cysts: A unified concept on management. Am J Surg 1979;137:135-41.

4. Bradley EL, Gonzales AC, Clements JL. Acute pancreatic pseudocysts Incidence and complications. Ann Surg 1976;184:734-7.

5. Liguory C, Meduri B, Coelho JR, Ahl-Kampf C, Leger L. Traitement endoscopique d'un faux-kyste sur pancréas divisum. Chirurgie 1982;108:273-8.

6. Sahel J, Liguory C. Endoscopic treat- ment of pancreatic cysts: Preliminary results. Gastroenterology 1984;86:1227. (Abst)

7. Hershfield NB. Drainage of a pancreatic pseudocyst at A.R.C.P. Gastrointest Endosc 1984;20:269-70.

8. Kozarek RA, Brayko CM, Harlan J, Sanawski RA, Cintora 1, Kovak A. Endoscopic drainage of pancreatic pseudocysts. Gastrointest Endosc 1985;31:322-8.

9. Czaja J, Fisher M, Marin GA. Spontaneous resolution of pancreatic masses (pseudocysts?) appearing after acute alcoholic pancreatitis. Arch Intern Med 1975;135:558-62.

10. Rosenberg IK, Kahn JA, Walt AJ. Surgical experience with pancreatic pseudocysts. Am J Surg 1969;117:11-7.

11. Bradley EL, Clements L. Spontaneous resolution of pancreatic pseudocyst. Am J Surg 1975;129:23-8.

12. Sarles JC, Salasc B, Delecourt P, Wacchiero M, Gaeta L. Formations kystiques au cours des pancréatites chroniques: Orientations thérapeutiques. Gastroenterol Clin Biol 1982;6:857-62.

13. Winship D. Pancreatitis: Pancreatic pseudocysts and their complications. Gastroenterology 1977;73:592-603.

14. Gieman PK, Gibbons JC, Kaplan MS. Unusual diagnostic aspects and current management of pancreatic pseudocysts. Am Surg 1974:40:326-34.

15. Hancke S, Pedersen JF. Percutaneous puncture of pancreatic cysts guided by ultrasound. Surg Gynecol Obstet 1976;142;551-2.

16. Barkin JS, Smith FR, Pereias RJM, et al. Therapeutic percutaneous aspiration of pancreatic pseudocysts. Dig Dis Sci 1981;26:585-6.

17. Karlson KB, Martin EC, Fankuchen EI, Mattern RF, Schuitz RW, Casarella WJ. Percutaneous drainage of pancreatic pseudocysts and abscesses. Radiology 1982;142:619-24.

18. Laugier R, Sahel J, Cicero G, Camara $\mathrm{B}$, Sarles H. Traitement non chirurgical des kystes de pancréatite chronique calcifiante (resultats à long terme). Gastroenterol Clin Biol 1986;10:146A. (Abst)

19. Cremer M, Deviere J. Endoscopic management of pancreatic cysts and pseudocysts. Gastrointest Endosc 1986;32:367-8. 


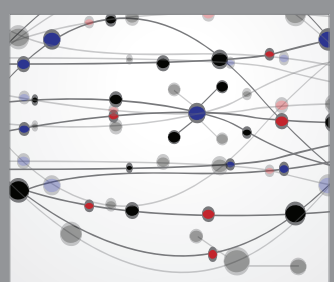

The Scientific World Journal
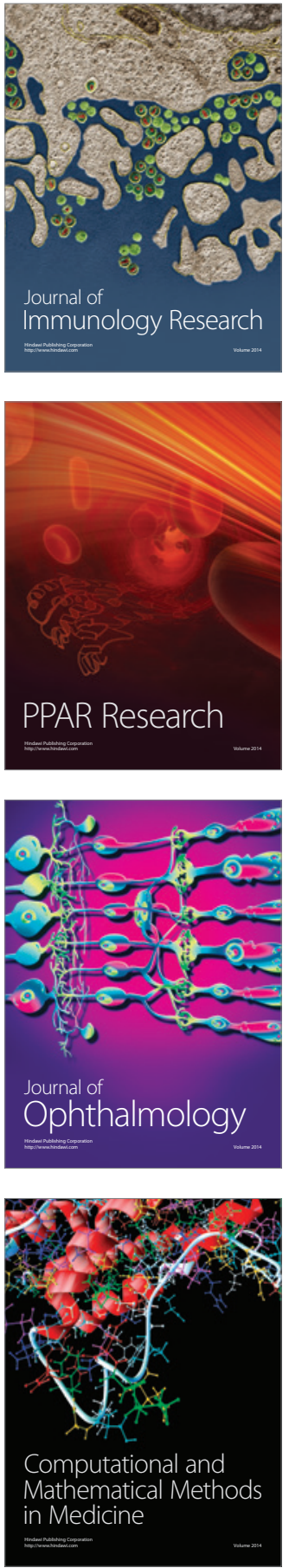

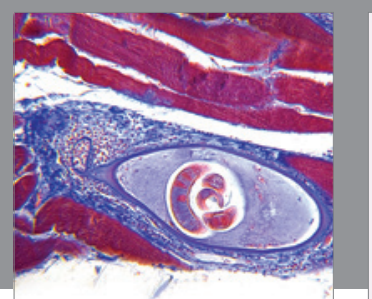

Gastroenterology Research and Practice

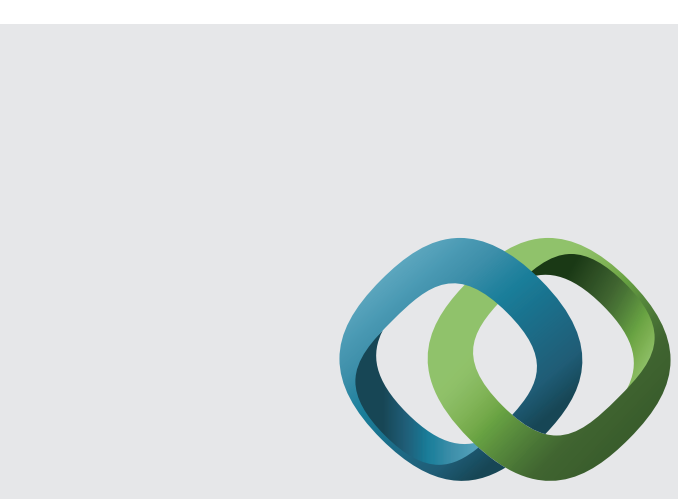

\section{Hindawi}

Submit your manuscripts at

http://www.hindawi.com
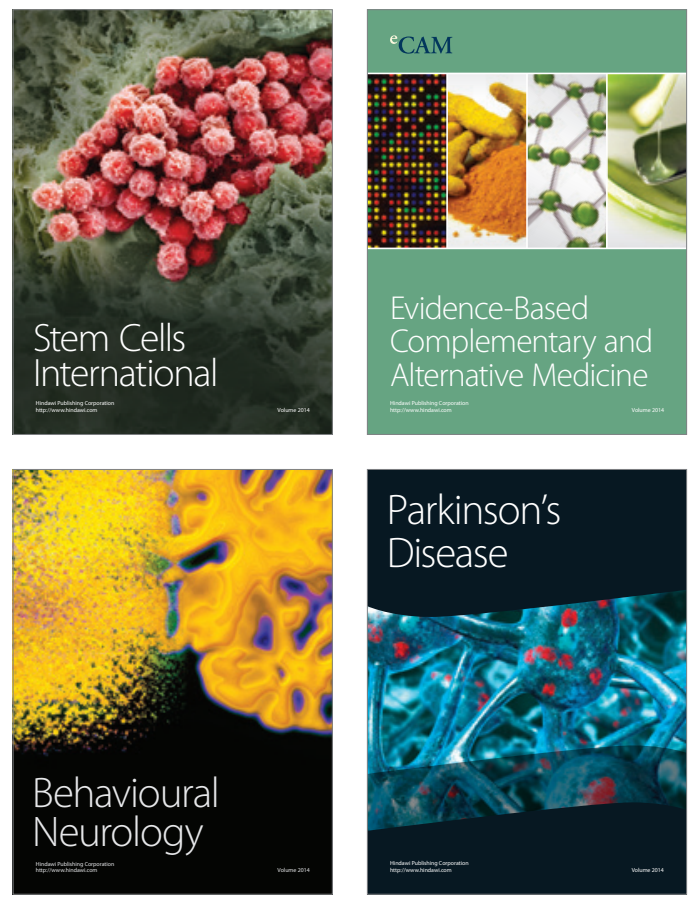
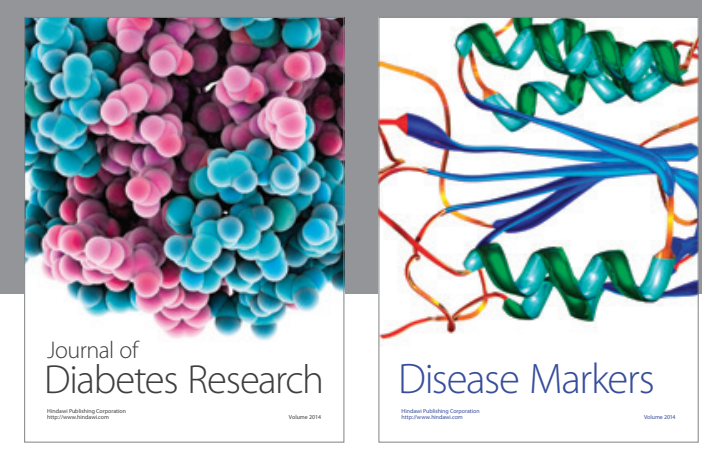

Disease Markers
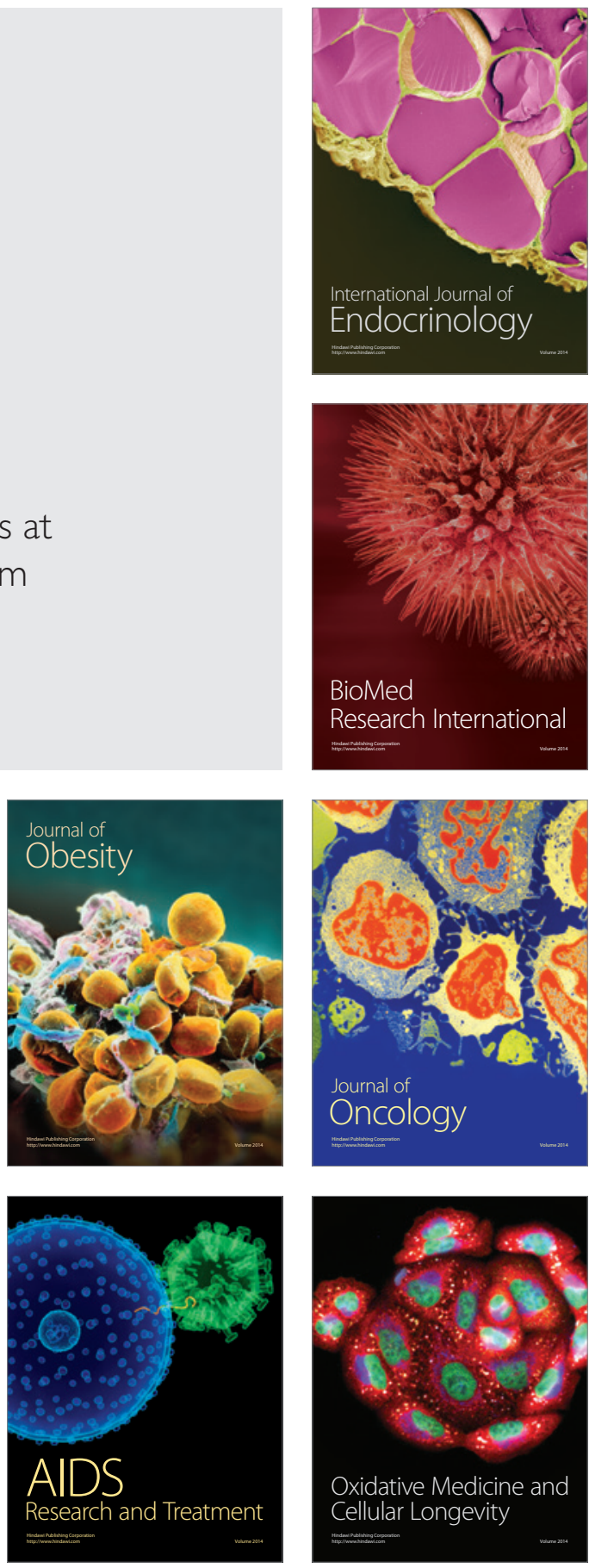